\title{
Perceived Significance of Improved Patient Data and Healthcare Services in the Formation of Inter-organizational Healthcare IT Governance
}

\author{
Tomi Dahlberg \\ Turku School of Economics At University of Turku, Finland \\ tomi.dahlberg@utu.fi
}

\begin{abstract}
IT is seen as the means to develop healthcare and social welfare services for citizens and to improve the quality of medical and social welfare data. This is deemed to require better IT cooperation between organizations. My research investigates the formation of voluntary inter-organizational IT governance in healthcare and social welfare IT engaging over 100 organizations. Attention is placed especially on the perceived benefits of IT governance. Results suggest that concrete benefits are necessary for the formation of interorganizational IT governance arrangements. The anticipated benefits of patient data improvement and short-term benefits were evaluated more important than the expected long-term improvements of healthcare and social welfare reforms.
\end{abstract}

Keywords: Healthcare IT, Social welfare IT, IT Governance.

\section{Introduction}

Healthcare and social welfare professionals, national governments and international organizations consider questions such as: How to arrange and provide healthcare and social welfare services for citizens? How to improve the integration and quality of patient / customer data? How to govern and manage information technology (IT) and patient / customer data as a part of healthcare and social welfare services?

Societal developments, especially the aging of population, make it necessary to consider reforms to national healthcare and social welfare systems [18]. Data mining, analysis, visualization etc. techniques offer huge potentials to improve healthcare and social welfare services [17]. At the same time the fragmentation and poor quality of data and data storages as well as lack of message and data model standards hamper electronic data transfer and the deployment of these potentials [11]. IT-enabled services are seen as one key element both for reforms and for data quality improvements, at the same time as healthcare and social welfare IT faces several "make ends meet" type challenges that limit the potential of IT [26].

According to an UN 2012 estimate [20], persons older than 60 years accounted for 11 per cent of the world's population. During the next four decades, the proportion of older population is projected to increase to 22 per cent [20]. Within the European Union (EU), including the country of this study, the demographic changes with longer 
life expectancies and lower birth rates have dramatic effects. In EU, dependency ratio is estimated to drop from 1:4 to 1:2, cost of (health and social) care to increase with 4$8 \%$ of GDP and work force to shrink with 20 million by 2025 [26]. Increasing demand for healthcare and social welfare services is deemed to require coordinated activities and better information sharing between social welfare, basic healthcare and specialized medical care services. The same is true for all groups with disabilities and special needs [12]. IT is seen to support reforms in two ways. Automation of routines, integration of information systems (IS), and the usage of data storages and electronic data transfer are expected to produce better services. Interoperability, standards and cooperation between organizations are needed for this. Secondly, new IT-based services are called for so that citizens are able to take more responsibility for their wellbeing and for living more healthily, are empowered to active aging with new types of work arrangements and longer participation to the activities of a society [26]. Ease of use and new health and social care models are necessary for this. Economic growth, markets and novel business models are needed to support needed innovations [26].

At the moment, fragmentation and inconsistency of healthcare and social welfare data appears to be more the norm than the exception [12], [17]. For example, out of the 194 member states of World Health Organization (WHO) only 34 members were able to provide reliable health data in 2012 [12]. A major reason for this is the way, how healthcare and social welfare service providers run their patient/customer ISs and databases [12]. They register medical measurements, events, radiographs, prescriptions, case summaries, etc., social welfare service actions, decisions etc., and other data into their unique databases. Data sharing remains challenging, even when organizations have purchased the same IS from the same vendor. Organization-specific implementations result in differences in data models, in data coding schemes and in data handling practices, which then prevent electronic data sharing [17]. Data structures and messages need to be standardized together with the related identification and authentication services and data transfer interfaces. Also data collection and processing practices need to be standardized to the extent of producing consistent data.

Organizational silos and limited coordination contribute to the existence of "making end needs" type challenges of healthcare and social welfare IT. Resources are insufficient as organizations develop similar IT solutions independently. Possibilities to recruit highly skilled specialists and to purchase rare IT assets or skills are limited due to financial, availability, size etc. constrains. The power of one organization is little in negotiations with IT service vendors as compared to pooled purchases and negotiation power. The absence of established inter-organizational (IT) cooperation and governance arrangements limits cooperation to experience exchange instead of resource sharing and joint IT service development and operations.

The usage of IT to reform national healthcare and social welfare systems, to improve data quality and interoperability, and to solve the "making ends meet" challenges of IT resourcing lead to the same conclusion. Better inter-organizational IT cooperation and governance is needed. IT governance bodies should define clear objectives for IT cooperation, direct cooperation by agreeing accountabilities for plans, activities etc., and monitor cooperation by reviewing outcomes. National governments typically emphasize reforms' long-term benefits and impacts on data quality. Local 
professionals probably focus more on short-term service and data interoperability benefits and IT professionals may also wish to solve IT-specific challenges.

The current IT governance research addresses IT governance mainly within one organization [21], [23] with a few case studies as the exceptions. These case studies describe inter-organizational IT governance between related business units or partners in domestic [4, 5] or in global company [7] contexts. My research examines the formation of voluntary inter-organizational IT governance engaging a large number of independent healthcare and social welfare organizations. Research has also examined the benefits of IT governance limitedly. Financial metrics such as cost, revenue and return on assets have been investigated [23]. My study draws on the resource based view (RBV), transaction cost economics (TCE) and social network theories to complement the theoretical basis. They address alliances (=inter-organizational governance) as a form of governance [6], [26], [28], have been used in prior IS research [e.g. [19], [24] and have rich metrics for the benefits of inter-organizational governance.

To summarize, with this research I investigate the formation of voluntary interorganizational IT governance between legally independent organizations. Special attention is paid to IT cooperation benefits during the formation of an IT governance arrangement. The two research questions are: What is the significance of IT cooperation benefits for the formation of inter-organizational IT governance? Secondly, how important are short-term benefits in healthcare and social welfare patient / customer data and in "making ends meet IT" as compared to long-term service improvements?

Section 2 explains how the objectives of this research were achieved and the research questions answered by theoretically discussing IT and health information governance, RBV, TCE and social network theory. Section 3 describes how that was done through a case study with a related expert survey. Results from the empirical case study and the survey are shown in Section 4. Finally, in Section 5, the theoretical and empirical findings of this study are discussed and conclusions are drawn.

\section{Theoretical Background}

This study follows the social network theory definition of inter-organizational (IT) governance [14]: "Network governance involves a select, persistent, and structured set of autonomous firms engaged in creating products or services based on implicit and open-ended contracts to adapt to environmental contingencies and to coordinate and safeguard exchanges. These contracts are socially_not legally-binding." The case I investigated has all characteristics of the definition although "firms" are nonprofit public sector organizations. The establishment of (IT) governance is one phase in its lifecycle, also called the formation of an alliance [6]. Literature is reviewed to understand, why do organizations decide to form alliances, such as formal IT governance arrangements? What benefits do participating organizations expect from that? Since IT governance research on inter-organizational governance is scarce, constructs from RBV, TCE and social network theory are reviewed to answer these questions. 
IT Governance and Health Information Governance research: As explained above, prior studies have examined mainly intra-organizational IT governance. However, [4] and [7] investigated IT governance arrangements within single-organization multiunit and [5] within value network contexts. Value networks included single buyer multi-vendor (contractual) and single service organizer - multi-partner (consensual) arrangements. The mentioned articles suggest that the formation of both intraorganizational and inter-organizational IT governance follow rather similar practices. De Haes et al. [7] explain how IT governance structures, processes and cooperation mechanisms could be extended from intra-organizational to inter-organizational settings. The generic purpose of IT governance is to "enable both business and IT to execute their responsibilities in support of business and in the creation of business value from IT investments". [7] It is noteworthy that IT governance benefits are classified into business (e.g. healthcare and social welfare services and better patient / customer data) and into IT performance benefits. Business and IT performance benefits are also built in into IT governacne best practice methods, especially COBIT.

The benefit proposition is that "IT governance effectiveness is positively associated with organizational performance" [16]. Mohamed et al. [16] note that the benefits of IT governance consist of financial, customer, learning and growth, and of internal and business process benefits (=the 4 dimensions of the balanced scorecard). Weill et al. investigated the business performance impacts of alternative IT governance arrangements with three types of measures; cost-efficient use of IT, business profitability and revenue growth [23]. Huang et al. [13] classified the IT performance impacts of IT governance into the efficiency of IT use, the breath of current IT use and the breath of potential IT use. Bradley et al [2] studied IT governance outcomes in US hospitals by dividing them into social risk management, technical risk management, market responsiveness, external relationship management and operational IT effectiveness. In summary, the current IT governance literature considers rather thinly, why organizations cooperate and what are the benefits of inter-organizational IT governance.

The definitions of health information governance [17], [11] differ slightly from those used in IT governance research and show how elusive the IT governance concept is. Definitions emphasize "standardizing the management, policy design and risk management associated with information". Hovenga [12] investigated the versatile beneficial impacts of health information governance on one nation's (Australia) healthcare system. Potential benefits include improved evaluating and comparing of health outcomes from transitioning to digital environment, and better sustainability of heath systems. Other potential benefits are: improved leadership and governance (national strategic policy framework, health process management and strategic health policy frameworks); financing of healthcare (health insurance versus funding, terminology and coding systems etc.); health workforce (planning of roles, occupational categories, workforce registration, licensing etc.); medical products, devices and technologies (device and technology types, medical device regulations, medical device nomenclature, etc.); health service delivery types and regulations (harmonization of service delivery data, accessing healthcare services, planning and managing resources 
and health service delivery, epidemiology issues etc.); and information and research (for leaders and governors, other key decision makers, professionals, researchers etc.)

RBV, TCE and Social Network Theory research: RBV, TCE and social network theory [25] regard single organizations (vertical governance in TCE), markets (market governance in TCE) and networks / alliances (hierarchical or relational governance in TCE) as alternative governance models. (Strategic) alliances are voluntary cooperative inter-organizational agreements that aim to produce competitive advantages for alliance partners [6]. Within the context of this research, voluntary interorganizational IT governance is seen as an arrangement to agree how to govern (the management of) IT as an alliance with the motive to provide better healthcare / social welfare services for citizens through the means of IT and digital data deployment.

Barney [1] introduced the work of Penrose into IS research. RBV sees each organization unique [1], [24], as an equivalent to the broad set of tangible and intangible resources that it owns (semi-)permanently [9], [24]. Intangible resources include IT and information, and the usage arrangements of resources. The resources of the organization as a whole, and especially imperfectly mobile, non-imitable and nonsubstitutable resources determine the organization's value creation potential. RBV proposes that inter-organizational cooperation happens, if cooperation provides winwin value for the participants by pooling, aggregating, sharing and exchanging their valuable unique resources, and if such value cannot be better achieved in other ways.

Barney proposed that four properties of (IT) resources make them unique, valuable, rare, imperfectly imitable and non-substitutable [1]. Das et al. [6] treat mobility, imitability and substitutability as the basic unique properties of resources. Resources have also other attributes. They can be property based (human, intellectual or physical) or knowledge based (organizational, technological or managerial). Resources can be supplementary, complementary, surplus or wasteful. Melville et al. [15] classify IT resources into human and technical. According to Wiengarten et al. [24] IT resources are typically complementary to an organization's business resources. They can be complementary to other assets, capabilities, organizational processes, firm attributes, information, knowledge, etc. controlled by the organization. IT resources can thus be complementary both to non-IT resources and to other IT resources.

Wiengarten et al. [24] propose that IT resources provide value to an organization / alliance: "(1) When IT resources are aligned, integrated or coupled with organizational processes such as knowledge processes, or management processes, synergies and higher-order capabilities can be created. (2) Moreover, these higher-order capabilities may result in long-term performance improvement. (3) To develop these long-term performance enhancement capabilities, a firm may need to redesign its processes in terms of its employed resources (i.e. human resources and facilities)." Park et al. [19] classify the outcomes of resource properties as: (1) conserve resources, (2) share risks, (3) obtain information, (4) access complementary resources, (5) reduce product development costs, (6) improve technological capabilities and (7) enhance reliability.

TCE introduced by Coase was developed further and operationalized by Williamson [25]. He introduced asset specificity, uncertainty and transaction frequency as the determinants by which firms (=organizations) choose to make, buy or ally while they execute transactions. Geyskens et al. [9] define relational governance (alliance) as: 
"Governance modes characterized by the parties to a transaction jointly developing policies directed toward the achievement of certain goals." The voluntary interorganizational IT governance arrangement investigated here is relational in its nature.

Geyskens et al. [9] provide operationalized construct definitions and metrics for asset specificity, volume uncertainty, technological uncertainty and behavioral uncertainty. The metrics of asset specificity include organization nature, (healthcare / social welfare) product and services, customer (patient) complexity, need of training to use assets etc. Volume uncertainty metrics contain expected volume fluctuation and uncertainty of volume estimates, and the stability of industry (e.g. healthcare and social welfare) volumes, ability to predict trends, etc. Technology uncertainly is captured with such metrics as technology improvement and specification changes. The metrics of behavioral uncertainty include buyer expectations, (healthcare and social welfare IT services) seller competition, price quality in relation to seller competition and the importance on non-selling activities (e.g. support to IT services). Ability to codify transactions (for example, patient/customer data) and task complexity (for example, the design of enterprise architecture) are other metrics of asset specificity. Similarly, intention to conduct R\&D (for example, the development of novel IT-enabled selfdiagnostic healthcare services to citizens) is another technology uncertainty metric.

Geyskens et al. [9] divided the performance impacts (benefits) of TCE into cost inclusive and into cost exclusive categories. Levels and changes of revenues and costs, abnormal returns on assets (e.g. IT investments) are cost inclusive metrics. Levels and changes of activities are cost exclusive. Other metrics used so far include speed of development (e.g., time needed to execute healthcare and social welfare IT projects), and level and changes in quality (for example, in the quality of patient / customer data) [8]. Wang et al. [22] investigated the impacts of information visibility (assets specificity), inter-organizational supply chain flexibility (behavioral uncertainty) and integration (technological uncertainty) on supply chain performance. They used three measures for outcomes; fit of work practices between organizations, fit of work outcomes between individuals and fit in routines between organizations [22, appendix].

The social network theory started to investigate the social embeddedness of institutions with the so-called structural macro-level studies [10]. Markets are seen to consist of social rather than economic structures [10], and to contain strong or weak ties between people and organizations [28]. Social network theory proposes that an organization perceives the world through a network with a structural rather than an individual lens. Such perception gives the organization a more complete, but not necessary only view to reality. A network, such as healthcare and social welfare IT cooperation, offers opportunities and constraints to participants, which then guide actions taken.

Embeddedness of organizations is the key construct of social network theory. Embeddedness impacts actions that organizations take in their responses to markets. The longer and the tighter the relationships between organizations, the more embedded they are [28]. Zaheer et al. [28] discovered that organizations in tight networks are likely to take different actions than traditional un-networked organizations. Social capital and structural holes are other key constructs. Social capital describes the value of connections between organizations. Structural hole means the lack of a straight connection between two organizations. Social network governance uses social me- 
chanisms - cooperation mechanisms in traditional IT governance terminology - to guide actions and to solve network problems. Jones et al. [14] identified four social mechanisms; restrictions to access the network, collective sanctions, use of social memory and cultural processes. Restricted access and cultural processes are used to coordinate network operations. Collective sanctions and social memory are used to safeguard network operations. Brass et al. [3] classified networks on the basis of following characteristics: strategic alliance and collaboration, flow of information, affect or friendship, good and services work flow, influence or advice, and overlapping group memberships. Organizations form and join networks motivated by their needs, such as responding to market challenges (e.g. reforms) and need to development services.

Antecedents to collaborate vary at personal, inter-unit (internal units of an organization) and inter-organizational (between organizations) levels. Actor similarities, personalities, proximity and organizational structure, and environmental factors are personal level antecedents. Interpersonal ties, functional ties and organizational processes, and control mechanisms are inter-unit antecedents. Personal and inter-unit antecedents are valid also on inter-organizational level. Motives (new resources, uncertainty reduction, bigger legitimacy, common goals), learning about an industry or about networking, relational trust, common norms and monitoring, equity between partners and context affecting all participating organizations constitute interorganizational antecedents to collaborate [3]. Networks transmit information to equalize common knowledge and share innovations, mediate issues between organizations and individuals and share resources and power among network participants.

\section{Case and Expert Survey}

The researcher acted as a consultant during the formation of the investigated IT governance arrangement. Thus, reflective observation approach in a single case context is used. Guidelines for case studies [27] and for the building of research constructs are followed. For research, I have access to the full range of the case material. Volumewise workshop materials represent the largest proportion of empirical data. Workshop materials range from RACI charts to discussion notes; from agendas to thick prereading documents; and from draft revisions of the Law on Arranging Social Welfare and Health Care Services to the drafts and final memorandums of the project. Empirical data includes also memos, emails, presentation slides, and answers to Q/A.

The case covers the formation of voluntary inter-organizational IT governance for healthcare and social welfare IT in one of Finland's five Special Catchment Areas. The arrangement engages over 100 organizations; 68 cities, towns or municipalities, 5 healthcare districts, 9 hospitals including one university central hospital, 33 healthcare centers and 5 social welfare development districts. The idea was to use this case as the pilot for the other four areas and to provide input to law reform work. No IT governance arrangement had existed earlier between the organizations. The IT governance arrangement also consolidated the IT services of specialized medical care, basic health care and social welfare services for the first time. 
The project group that accomplished the task during 9 months consisted of 17 persons. They included the chief medical officer of one healthcare district, three healthcare district CIOs, the CIO of a major city, two enterprise architects, three specialist from social welfare development centers and the National Institute for Health and Welfare, one IT expert from another Special Catchment Area, two senior advisors from the Ministry of Social Affairs and Health, two senior advisors from the Association of Local and Regional Authorities plus the researcher as a consultant. The proposal of the project was accepted in February 2014 and its implementation started immediately. In March 2014, the Government of Finland decided to give the responsibility for the arrangement of healthcare and social welfare services to five "Special Catchment Areas". In June 2014, all political parties agreed the same. The proposal accepted in February is in compliance with these national level decisions.

The definition of concrete IT cooperation benefits was one task accomplished by the project. Nine concrete benefits were defined. Need to improve patient / customer data interoperability and data quality was considered the most burning challenge in the current status. Four additional specific data related benefits were defined for this reason. The 13 statements are shown in appendix 1. Also the connections between each statement and the theoretical constructs reviewed in Section 2 are shown.

A web-enabled self-administered survey was conducted to offer leading healthcare and social welfare experts an opportunity to evaluate the defined benefits and other aspects of the proposed IT governance arrangement prior its acceptance. This study uses only that part of the available data that concentrates on IT governance benefits. In addition to the IT governance benefit statements, the survey included demographic, situational and behavioral control variables also shown in Appendix 1. The survey items of IT cooperation benefits and the behavioral control variables were formulated into statements. Respondents were asked to evaluate each statement on a 7-point Likert scale from totally disagree $(=1)$ to totally agree $(=7)$.

An invitation to participate to the survey was emailed to 260 healthcare and social welfare experts throughout the country. After one reminder 68 responses $(26 \%$ response rate) were received. Survey respondents had the following characteristics:

- Slightly over half (37) of the 68 responses were from the geographic area of the case.

- Seven respondents participated to the formation of the inter-organizational IT governance arrangement. Statistical comparisons to other respondents were not made.

- Slightly over half (53) of the respondents worked in healthcare districts, $37 \%$ in cities, towns or municipalities, and $10 \%$ in other organizations.

- $66 \%$ were executives and managers and $34 \%$ were experts.

- $43 \%$ were healthcare or social welfare managers or executives and $12 \%$ specialists. CIOs and IT managers accounted for $23 \%$ and IT specialists for $22 \%$.

- Healthcare and social welfare executives and managers had worked in those positions on average for 15.9 years, experts for 12.7 years. Healthcare and social welfare CIOs and IT managers had worked in those positions on average for 7.2 years and IT experts for 8.8 years. 
The expectation drawn from the theoretical background was that expert evaluations would be high. On the other hand, no expectations were made regarding which benefits would be evaluated most important. Due to the limited number of responses multivariate statistical methods, including structured equation models, could not be used. Statistical analysis on the differences in the means of survey items was done with the two-tailed Stu dent t-test. For statistical analyses responses to behavioral control variables were classified into agree (values 5-7) and non-agree (values 1-3) classes.

\section{$4 \quad$ Results}

The need for IT cooperation by pooling, sharing and exchanging IT resources with envisioned concrete benefits was decisive for the willingness to participate to the formation of the IT governance arrangement. The project started with an effort to rely solely on IT governance knowledge. That approach proved insufficient in terms of participants' and organizations' commitment. One of the CIOs coined the problem: "Although I understand the governance matrix with RACI roles that we crafted..., that has been totally useless in my organization. Doctors do not understand from the matrix the benefits of IT cooperation. They ask me, why should we use time to consider inter-organizational IT governance when there are so many burning IT issues in our own organization." Improved quality of patient / customer data was also regarded important. At the dissemination presentations of the drafted IT governance model one medical director stated: "Actually, I only want to know, when will I get reliable, consistent and holistic patient and medical data from all the data sources we have."

As expected the evaluations of IT governance benefits were very high on the scale from 1 (low value) to 7 (high value) as Table 1 shows. More specific results are:

1. Patient / customer information benefits were considered more important than generic IT governance benefits.

2. Making ends meet benefits were considered more important than the long-term improvements of reforms to healthcare and social welfare services. The background documents used in the project discuss the necessities to improve the national healthcare and social welfare systems. Those appear to remain abstract in comparison to concrete needs to improve services and related IT. Alternatively it is possible that the solving of concrete challenges is seen to preside reforms.

3. None of the demographic, situational or behavioral control variables were related to variations in the means of IT governance benefits in statistically significant way (t-test). Thus, in this survey, IT governance benefits were evaluated similarly independent of geographic location, profession, professional status, length of experience, attitudes toward IT or attitudes toward the use of IT within respondent's organization. Table 1 shows averages by professional orientation. 
Table 1. Results of the expert survey

\begin{tabular}{|c|c|c|c|c|c|}
\hline Survey Item & Mean & Median & \begin{tabular}{|c|} 
Proportion of \\
strongly agree
\end{tabular} & $\begin{array}{c}\begin{array}{c}\text { Mean, Biz } \\
\text { experts }\end{array} \\
\end{array}$ & $\begin{array}{c}\begin{array}{c}\text { Mean, IT } \\
\text { experts }\end{array} \\
\end{array}$ \\
\hline \multicolumn{6}{|c|}{$\begin{array}{l}\text { Generic IT Governance Benefits: Improved Healthcare and Social Welfare Services (Resulting from Reforms) - - Inter-Organizationa } \\
\text { Well-Organized Cooperation in Healthcare and Social Welfare IT Is Needed in Order to ... }\end{array}$} \\
\hline \begin{tabular}{|l|} 
Increase the interoperability of patient/customer information \\
systems and data storages
\end{tabular} & 6.3 & 6.5 & $86.8 \%$ & 6.3 & 6.3 \\
\hline $\begin{array}{l}\text { Ensure ability to participate to the national level development } \\
\text { of healthcare and social welfare services }\end{array}$ & 5.8 & 6.0 & $72.1 \%$ & 5.8 & 5.7 \\
\hline $\begin{array}{l}\text { Ensure the availability of equal healthcare and social welfare } \\
\text { services everywhere in the country }\end{array}$ & 5.7 & 6.0 & $67.6 \%$ & 5.8 & 5.5 \\
\hline \multicolumn{6}{|c|}{$\begin{array}{l}\text { Generic IT Governance Benefits: Bnefits from Better Usage of Resources ( Making Ends Meet) - Inter-Organizational Well-Organized } \\
\text { Cooperation in Healthcare and Social Welfare IT Is Needed in Order to ... }\end{array}$} \\
\hline $\begin{array}{l}\text { Avoid the development of overlapping and difficult to integrate } \\
\text { IT services }\end{array}$ & 6.4 & 7.0 & $86.8 \%$ & 6.4 & 6.4 \\
\hline Create enterprise architectures & 6.1 & 6.0 & $79.4 \%$ & 6.2 & 6.0 \\
\hline (Co-)source IT-services cost-efficiently and effectively & 6.0 & 6.0 & $75.0 \%$ & 6.2 & 5.7 \\
\hline $\begin{array}{l}\text { Implement national level healthcare and social welfare IT } \\
\text { services efficiently and effectively in the area }\end{array}$ & 6.0 & 6.0 & $75.0 \%$ & 6.2 & 5.9 \\
\hline Use IT resources and assets efficiently and effectively & 5.7 & 6.0 & $70.6 \%$ & 5.7 & 5.8 \\
\hline $\begin{array}{l}\text { Ensure access to specialized capabilities and competencies } \\
\text { everywhere in the area }\end{array}$ & 5.8 & 6.0 & $69.1 \%$ & 5.9 & 5.7 \\
\hline \multicolumn{6}{|c|}{$\begin{array}{l}\text { IT Governance Benefits from Improved Patient Data - The development of patient / customer information systems and data storages } \\
\text { requires ... }\end{array}$} \\
\hline Tighter cooperation on national level & 6.4 & 7.0 & $89.7 \%$ & 6.4 & 6.3 \\
\hline $\begin{array}{l}\text { Tighter cooperation on regional level (this Special Catchment } \\
\text { Area) }\end{array}$ & 6.3 & 6.5 & $85.3 \%$ & 6.4 & 6.1 \\
\hline The creation of jointly agreed data models and sticking to them & 6.3 & 7.0 & $85.3 \%$ & 6.4 & 6.3 \\
\hline Tighter cooperation between healthcare and social welfare & 6.3 & 7.0 & $79.4 \%$ & 6.3 & 6.4 \\
\hline
\end{tabular}

\section{$5 \quad$ Discussion and Conclusions}

This research shows that IT governance knowledge alone was insufficient for the formation of inter-organizational IT governance arrangement in the investigated case. Results suggest that need to cooperate with concrete benefits is critical to the formation of inter-organizational IT governance. This is the answer to the first research question presented in section one. Improvements to patient / customer data were perceived more important than long-term improvements to healthcare and social welfare services. The solving of making ends meet issues were also evaluated more important than long-term improvements to healthcare and social welfare services. Additional studies are necessary to verify these results, as this research is a single case study.

This research opens up news venues for IT governance and health information governacne research, for which RBV, TCE and social network theories offer rich and theoretically proven basis. The mentioned research traditions address three governance arrangements, single organization, markets and alliances / networks. So far IT and health information governance research has investigated mainly single organizations. IT governance arrangements could be compared in various contexts such as IT or data outsourcing including cloud services, supplier-customer networks, value chain orchestration or virtual organizations. Health information governance is by nature 
largely inter-organizational. Linking of inter-organizational governance research approaches to this context is another possible research direction.

The advice to practitioners is to pay serious attention to concrete level IT governance benefits when inter-organizational IT governance arrangements are designed. In national reforms of healthcare and social welfare sectors, concrete advancements in the quality of patient / customer data have a key role. It is especially important to make the long-term improvement objectives of reforms operational and concrete in order to entice experts to take necessary development efforts. This probably requires that long-term healthcare and social welfare reform objectives, such as the empowerment to active aging, be turned into measurable short-term milestones.

\section{References}

1. Barney, J.B.: Firm Resources and Sustained Competitive Advantage. J. Manage. 17(1), 99-120 (1991)

2. Bradley, R.V., Byrd, T.A., Pridmore, J.L., Thrasher, E., Pratt, R.M., Mbarika, V.W.: An Empirical Examination of Antecedents and Consequences of IT Governance in US Hospitals. J. Inf. Technol. 27(3), 156-177 (2012)

3. Brass, D.J., Galaskiewicz, J., Greve, H.R., Tsai, W.: Taking Stock of Networks and Organizations: a Multilevel Perspective. Acad. Manage. J. 47(6), 795-817 (2004)

4. Croteau, A.-M., Bergeron, F.: Interorganizational Governance of Information Technology. In: Proceedings of the 42nd Annual Hawaii International Conference on System Sciences (HICSS 2009), 8 pages. IEEE Press, New York (2009)

5. Croteau, A.-M., Bergeron, F., Dubsky, J.: Contractual and Consensual Profiles for an Interorganizational Governance of Information Technology. International Business Research 6(9), 30-43 (2013)

6. Das, T.K., Teng, B.-S.: A Resource-Based Theory of Strategic Alliances. J. Manage. 26(1), 31-61 (2000)

7. De Haes, S., Van Grembergen, W., Gemke, D., Thorp, J.: Inter-Organizational Governance of Information Technology: Learning from a Global Multi-Business-Unit Environment. International Journal of IT/Business Alignment and Governance 3(1), 27-46 (2013)

8. Gereffi, G., Humphrey, J., Sturgeon, T.: The governance of global value chains. Rev. Int. Polit. Econ. 12(1), 78-104 (2005)

9. Geyskens, I., Steenkamp, J.-B.E.M., Kumar, N.: Make, Buy, or Ally: A Transaction Cost Theory Meta-Analysis. Acad. Manage. J. 49(3), 519-543 (2006)

10. Granovetter, M.S.: Economic Action and Social Structure: The Problem of Embeddedness. Am. J. Sociol. 91, 481-510 (1985)

11. Hovenga, E.J.S.: National Healthcare Systems and the Need for Health Information Governance. In: Hovenga, E.J.S., Grain, H. (eds.) Health Information Governance in a Digital Environment. Studies in Health Technology and Informatics, vol. 193, pp. 3-23. IOS Press, Amsterdam (2013)

12. Hovenga, E.J.S.: Impact of Data Governance on a Nation's Healthcare System Building Blocks. In: Hovenga, E.J.S., Grain, H. (eds.) Health Information Governance in a Digital Environment. Studies in Health Technology and Informatics, vol. 193, pp. 24-66. IOS Press, Amsterdam (2013) 
13. Huang, R., Zmud, R.W., Price, L.R.: Influencing the Effectiveness of IT Governance Practices through Steering Committees and Communication Policies. Eur. J. Inform. Syst. 19(16), 288-302 (2010)

14. Jones, C., Hesterly, W.S., Borgatti, S.P.: A General Theory of Network Governance: Exchange Conditions and Social Mechanisms. Acad. Manage. Rev. 22(4), 911-945 (1997)

15. Melville, N., Kraemer, K., Gurbaxani, V.: Information Technology and Organizational Performance: An Integrative Model of IT Business Value. MIS Quart. 28(2), 283-322 (2004)

16. Mohamed, N., Singh, G.: A Conceptual Framework for Information Technology Governance Effectiveness in Private Organizations. Information Management \& Computer Security 20(2), 88-106 (2010)

17. Nahar, J., Imam, T., Tickle, K.S.: Issues of Data Governance Associated with Data Mining in Medical Research: Experiences from an Empirical Study. In: Hovenga, E.J.S., Grain, H. (eds.) Health Information Governance in a Digital Environment. Studies in Health Technology and Informatics, vol. 193, pp. 332-361. IOS Press, Amsterdam (2013)

18. Obi, T., Auffret, J.-P., Iwasaki, N.: Aging Society and ICT: Global Silver Innovation. IOS Press, Amsterdam (2013)

19. Park, N.K., Mezias, J.M., Song, J.: A Resource-based View of Strategic Alliances and Firm Value in the Electronic Marketplace. J. Manage. 30(1), 7-27 (2004)

20. United Nations: World Population Prospects: The 2012 Revision. United Nations, Department of Economic and Social Affairs (2014) Downloadable open data excel spreadsheet,

http://esa.un.org/wpp/WPP2 012_POP_F13_A_OLD_AGE_DEPENDENCY_R ATIO_1564.XLS

21. Van Grembergen, W., De Haes, S.: Implementing Information Technology Governance: Models, Practices and Cases. Idea Group Global, Hershey (2008)

22. Wang, E.T.G., Wei, H.-L.: Interorganizational Governance Value Creation: Coordinating for Information Visibility and Flexibility in Supply Chains. Decision Sci. 38(4), 647-674 (2007)

23. Weill, P., Ross, J.: IT Governance: How Top Performers Manage IT Decision Rights for Superior Results. Harvard Business School Press, Boston (2004)

24. Wiengarten, F., Humphreys, P., Cao, G., McHugh, M.: Exploring the Important Role of Organizational Factors in IT Business Value: Taking a Contingency Perspective on the Resource-Based View. Int J. Manag. Rev. 15(1), 30-46 (2013)

25. Williamson, O.E.: The Economic Institutions of Capitalism. Free Press, New York (1985)

26. Wintley-Jensen, P.: EU Activities on Aging. In: Obi, T., Auffret, J.-P., Iwasaki, N. (eds.) Aging Society and ICT: Global Silver Innovation, pp. 180-187. IOS Press, Amsterdam (2013)

27. Yin, R.K.: Case Study Research, Design and Methods, 4th edn. SAGE publications, Thousand Oaks (2009)

28. Zaheer, A., Gözübüyük, R., Milanov, H.: It's the Connections: The Network Perspective in Interorganizational Research. Acad. Manage. Perspect 24(1), 62-77 (2010) 


\section{Appendix 1}

Operational definitions of IT governance benefits used also as survey items with their references to theoretical constructs reviewed as the theoretical basis of the research

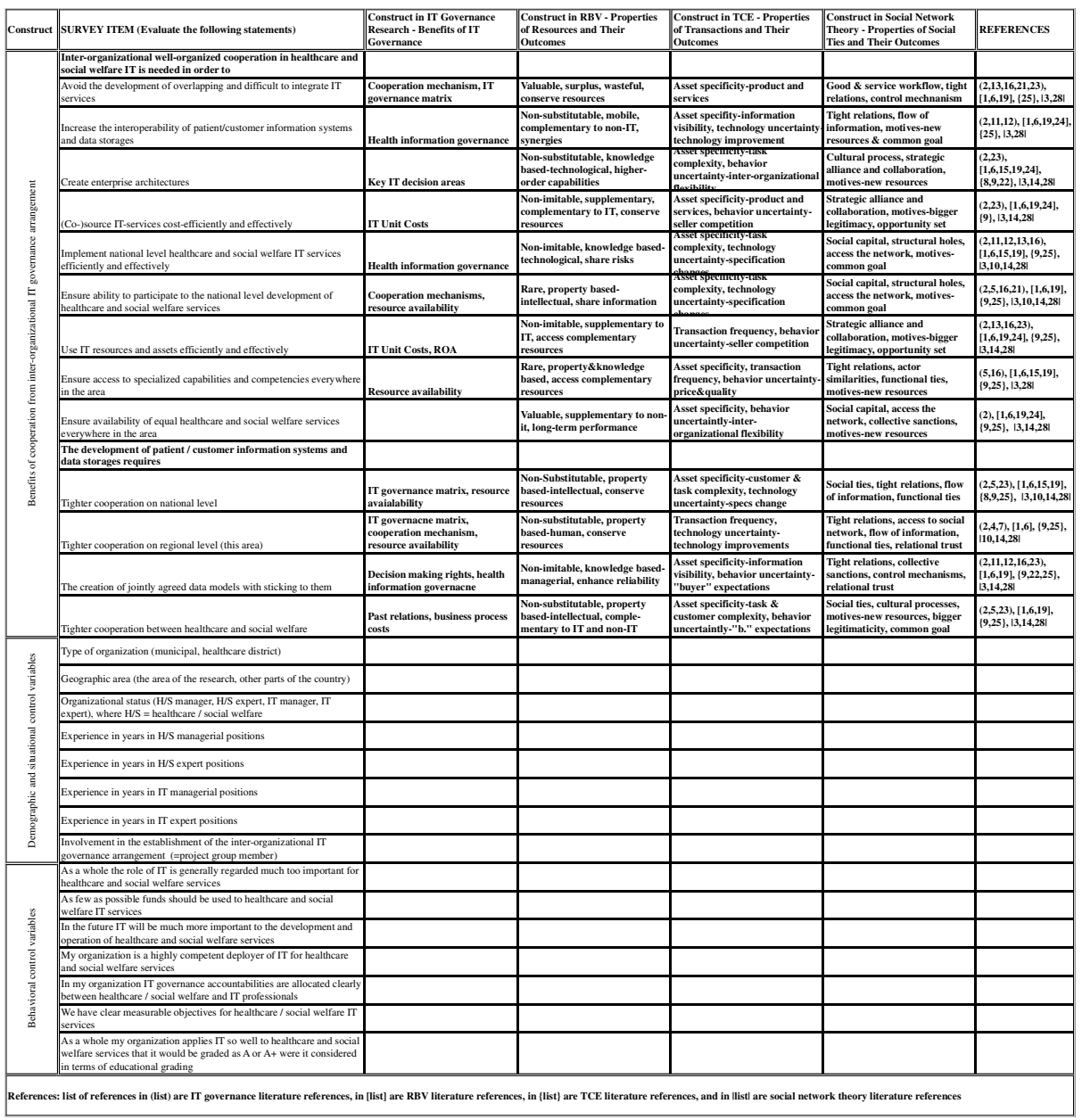

